\title{
SIMBOL JARI TANGAN SEDERHANA DALAM PEMBELAJARAN ANGKLUNG UNTUK SISWA SEKOLAH DASAR
}

\author{
Eka Yulyawan Kurniawan \\ Prodi PGSD FKIP Universitas Muhammadiyah Tangerang \\ Email: ekayeka88@gmail.com
}

\begin{abstract}
Angklung is an Indonesian traditional musical instrument that is studied by several Schools including Elementary Schools, because angklung does have a high educational value, in addition to training musical taste, creativity can also make students become more responsible and collaborate. But in the learning process, it is not uncommon for elementary school students to have difficulty playing angklung together, this is a problem that exists in the field, because angklung games are not individual but group games, so it requires considerable training time in the learning process. this actually can be tricked by angklung learning methods using simple finger symbols, where the teacher can later teach with the finger symbol. This study uses a qualitative method in which the writer tells the angklung learning process based on facts in the field. It is expected that by using the simple symbol method the difficulty of learning angklung for elementary school students can be overcome, and later it will be easier for teachers to teach angklung in elementary schools.
\end{abstract}

Keywords: Angklung; Elementary School; Finger Symbols

\begin{abstract}
Abstrak
Angklung merupakan alat musik tradisional Indonesia yang dipelajari oleh beberapa Sekolah termasuk Sekolah Dasar, karena alat musik angklung memang memiliki nilai edukasi yang tinggi, selain untuk melatih rasa musikal, kreativitas juga bisa membuat siswa menjadi lebih tanggungjawab dan bekerjasama. Tetapi pada proses pembelajarannya tidak jarang siswa Sekolah Dasar mengalami kesulitan untuk memainkan angklung secara bersama-sama, hal ini merupakan permasalahan yang ada dilapangan, karena permainan angklung bukan permainan individu melainkan kelompok, jadi memerlukan waktu latihan yang cukup lama dalam proses pembelajarannya. hal ini sebenarnya bisa disiasati dengan metode pembelajaran angklung menggunakan simbol jari tangan sederhana, dimana guru nantinya bisa mengajarkan dengan simbol jari tangan. Penelitian ini menggunakan metode kualitatif dimana penulis menceritakan proses pembelajaran angklung berdasarkan fakta dilapangan. Diharapkan dengan menggunakan metode simbol sederhana kesulitan belajar angklung siswa Sekolah dasar bisa diatasi, dan nantinya akan mempermudah guru dalam mengajar angklung di Sekolah dasar.

Kata Kunci: Angklung; Sekolah Dasar; Simbol Jari Tangan
\end{abstract}

\begin{tabular}{llll}
\hline Received & $: 2020-05-27$ & Approved & $: 2020-06-14$ \\
Reviesed & $: 2020-06-02$ & Published & $: 2020-07-31$ \\
\hline
\end{tabular}

Jurnal Cakrawala Pendas is licensed under a Creative Commons AttributionShareAlike 4.0 International License.

\section{Pendahuluan}

Permainan angklung banyak sekali terdapat nilai-nilai pendidikan, selain untuk fungsi musikal dalam permainan angklug siswa belajar disiplin, bekerjasama, tanggungjawab dan saling menghargai satu sama lain. Oleh karena itu angklung banyak dipelajari di Sekolahsekolah, dari Sekolah Dasar sampai Tingkat kampus atau Universitas. Akan tetapi proses pembelajaran angklung tidaklah mudah, karena pada dasarnya permainan angklung adalah permainan berkelompok atau ansambel, dimana kekompakan adalah kunci utamanya.

Proses pembelajaran angklung di Sekolah Dasar dan di Kampus atau sanggar pasti berbeda, karena karakteristik anak Sekoh Dasar yang masih anak-anak pastilah berbeda dengan anak yang sudah dewasa, oleh karena itu metode yang digunakan dalam 
pembelajaran angklung haruslah disesuaikan dengan karakteristik siswa. Karakteristik anak usia Sekolah Dasar memiliki potensi untuk membangkan kreativitas musik. Melalui pembelajaran angklung siswa dilatih bekerjasama dalam membuat karya musik dengan temannya yang lain, berkomunikasi dan berdiskusi dalam proses pembuatan karya dengan menggunakan alat musik tradisional angklung. Menurut Witherington (Makmun, 1995) bahwa Usia 9-12 tahun memiliki ciri perkembangan sikap individualis sebagai tahap lanjut dari usia 6-9 tahun dengan ciri perkembangan sosial yang pesat. Pada tahapan ini anak/siswa berupaya semakin ingin mengenal siapa dirinya dengan membandingkan dirinya dengan teman sebayanya. Jika proses itu tanpa bimbingan, anak akan cenderung sukar beradaptasi dengan lingkungannya. Dapat dipahami bahwa sekolah memiliki tanggung jawab untuk menanggulanginya.

Maka dari itu penggunaan metode pembelajaran yang tepat pasti sangat berpengaruh terhadap efektifitas prosespembelajaran Menurut Sudjana (2005), mengemukakan metode pembelajaran ialah cara yang dipergunakan guru dalam mengadakan hubungan dengan siswa pada saat berlangsungnya pengajaran. Lebih lanjut, dalam Kamus Besar Bahasa Indonesia, (1999) metode adalah cara yang telah teratur dan terpikir baik-baik untuk mencapai suatu maksud. Berdasarkan definisi di atas, penulis dapat mengambil kesimpulan bahwa metode merupakan jalan atau cara yang ditempuh seseorang untuk mencapai tujuan yang diharapkan.

Pembelajaran angklung di Sekolah Dasar lebih efektif jika menggunakan metode simbol, penggunaan simbol dalam belajar angklung bisa menggunakan jari tangan. Penggunaan simbol jari tangan dalam pembelajaran angklung tidak hanya untuk siswa Sekolah Dasar saja, bahkan untuk orang dewasa, banyak yang sudah menggunakan metode ini, namun berbeda-beda dalam penggunaan simbolnya. Sedangkan untuk anak usia Sekolah Dasar simbol yang digunakan hendaklah yang sangat sederhana.

Proses dalam pembelajaran angklung memiliki beberapa tahapan yang diawali dengan pengenalan instrumen atau alat musik angklung, yang terdiri dari satu oktaf atau lebih, dan memiliki berbagai ukuran dari mulai yang kecil hingga yang besar, setelah itu cara memainkan angklung, posisi tubuh tangan dan cara membunyikannya. Menurut Soeharto (1989) pengenalan terhadap alat musik, biasanya dimulai dari klasifikasi atau penggolongannya. Sebab untuk penentuan golongan, sedikit banyak diperlukan pengenalan, sehingga dengan usahanya penggolongan akan memaksa kita untuk semakin mengenalnya, lebih-lebih bila penggolongan kita lakukan dari berbagai segi

\section{Metode Penelitian}

Metode penelitian yang dipakai dalam penelitian ini yaitu deskriftif kualitatif, deskriftif kualitatif yaitu suatu pendekatan untuk membuat gambaran - gambaran mengenai situasi atau kejadian dengan menggunakan data yang dinyatakan secara verbal dan kualifikasinya. Serta dengan menganalisis setiap permasalahan yang ada pada saat penelitian yang bersifat teoritis maupun praktek. Menurut Nawawi (1995), Febriyanto (2016) mengemukakan bahwa penelitian deskriptif merupakan penelitian yang mengungkapkan suatu masalah, keadaan atau peristiwa sebagaimana adanya, sehingga bersifat sekedar untuk mengungkapkan fakta (Fact Finding).

Peneliti melakukan pendekatan evaluasi dimana setiap kegiatan penelitian selalu melakukan evaluasi agar proses pembelajaran angklung dapat berjalan maksimal. Penelitian Evaluasi merupakan bagian dari evaluasi dan juga merupakan bagian dari penelitian. Sebagai bagian dari evaluasi, penelitian evaluasi juga berfungsi sebagai evaluasi yaitu proses untuk mengetahui seberapa jauh perencanaan dapat dilaksanakan dan seberapa jauh tujuan program 
tercapai. Lebih kanjut, Sugiyono (2014), Saputra (2017), Saputra at al (2019) menggunakan penelitian evaluasi, maka data yang diperoleh akan lebih akurat, lengkap, valid, reliable dan obyektif.

Penelitian ini peneliti akan mendeskripsikan proses pelatihan angklung dengan menggunakan simbol jari sederhana untuk anak Sekolah Dasar, dimana dalam proses pembelajarannya melibatkan sekelompok siswa kelas III Sekolah Dasar di SD Mutiara Hati Kota Tangerang. Tahapan proses penelitian digambarkan seperti gambar di bawah:

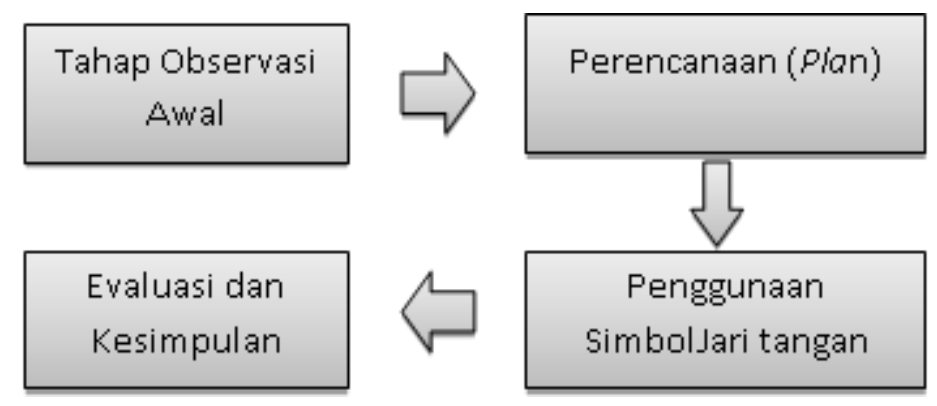

Gambar 1. Tahapan Penelitian

Instrument dalam penelitian kualitatif deskriptif ini adalah peneliti sendiri sebagai human instrument yaitu berfungsi sebagai yang menetapkan fokus penelitian, memilih informan sebagai sumberdata, menafsirkan data dan membuat kesimpulan dalam temuannya. Dalam pengumpulan data, baik itu wawancara ataupun observasi, peneliti juga memerlukan alat bantu seperti pedoman wawancara, pedoman observasi, buku catatan, alat perekam, dan kamera. Teknik pengumpulan data yang digunakan adalah Tringulasi data yaitu:

a. Observasi

Observasi adalah teknik pengumpulan data yang dilakukan melalui suatu pengamatan, dengan disertai pencatatan-pencatatan terhadap keadaan atau prilaku objek sasaran selama proses pembelajaran angklung menggunakan simbol jari sederhana. Melalui observasi, peneliti akan mengamati jalannya proses pembelajaran angklung.

b. Wawancara

Kegiatan wawancara merupakan interaksi Tanya-jawab antara peneliti dengan informan atau responden dimana dalam kegiatan tersebut peneliti mencari data yang dia butuhkan untuk penelitiannya dan yang menjadi informan dan responden adalah siswa dan guru kelas II SD Mutiara Hati Kota Tangerang. Wawancara bertujuan untuk memperkuat data yang telah ditemukan pada saat observasi bahkan melengkapi data yang belum didapat pada saat observasi.

c. Dokumentasi

Menurut Siyoto, dan Sodik (2015) tidak kalah penting dengan metode-metode yang lain, adalah metode dokumentasi, yaitu mencari data mengenai hal-hal atau variable yang berupa catatan, transkrip, buku, surat kabar, majalah, prasasti, notulen rapat, lengger, agenda, dan sebagainya. Metode dokumentasi digunakan untuk mengambil data berbentuk tulisan, nama siswa, gambar kegiatan, dan lain sebagainya yang berkaitan dengan pembahasan peneliti.

\section{Hasil dan Pembahasan}

Kegiatan pembelajaran angklung dilakukan setiap hari sabtu, agar tidak mengganggu pelajaran lain dan waktunya bisa lebih leluasa. Peserta pembelajaran angklung adalah siswa 
kelas 3 SD Mutiara Hati Kota Tangerang, siswa yang mengikuti pembelajaran angklung ada 21 siswa, siswa perempuan 12 dan siswa laki-laki 9. Sarana dan prasarana di SD Mutiara Hati bisa dibilang lengkap, dari mulai tempat latihan sampai alat musik angklung yang memadai, dalam arti kata seharusnya dengan sarana prasarana yang mendukung kegiatan pembelajaran angklung semestinya berjalan dengan lancar.

Proses pemblajaran angklung menggunakan media jari tangan sederhana memiliki beberapa tahapan pembelajaran, dari mulai pengenalan instrumen atau alat musik angklung, cara membunyikan dan posisi tubuh yang benar saat bermain angklung, hingga bagaimana cara membaca dan memahami simbol jari tangan yang akan digunakan dalam proses pembelajaran. Adapun tahapannya digambarkan seperti di bawah:

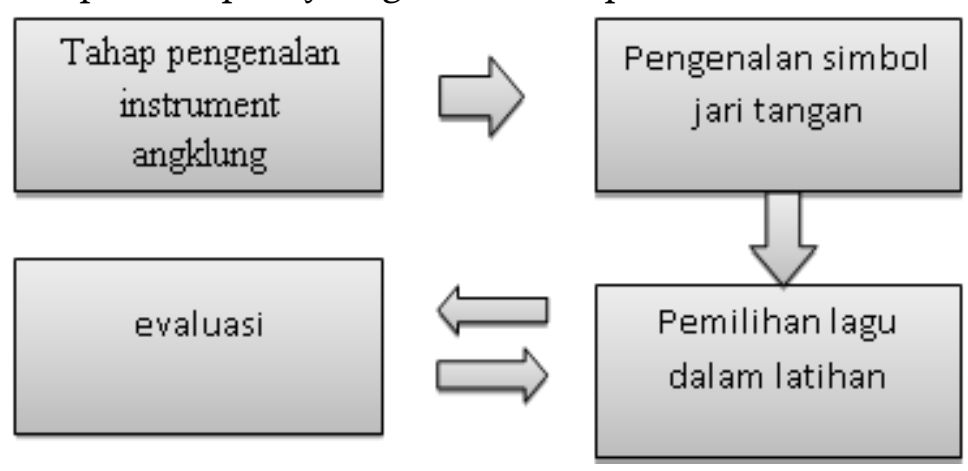

Gambar 2. Tahapan proses pembelajaran

\section{a. Tahapan Pengenalan Instrument Angklung}

Pada fase ini untuk siswa yang baru pertama kali memainkan angklung sangatlah penting, karena proses pengggenalan instrument sangat penting dalam proses pembelajaran bukan hanya bermain angklung, bahkan untuk alat musik apapun. Sebagian besar siswa di SD Mutiara Hati sudah mengetahui atau pernah melihat angklung, namun mereka belum pernah memainkannya. Dalam fase ini siswa akan diberikan penjelasan mengenai angklung, alat musik yang dimankan secara berkelompok, dengan jumlah instrumen lebih dari satu dan dengan ukuran yang berbeda-beda, Menurut Soeharto (1989) Pengenalan terhadap alat musik, biasanya dimulai dari klasifikasi atau penggolongannya. Sebab untuk penentuan golongan, sedikit banyak diperlukan pengenalan, sehingga dengan usahanya penggolongan akan memaksa kita untuk semakin mengenalnya, lebih - lebih bila penggolongan kita lakukan dari berbagai segi.

Setelah itu siswa belajar cara memainkan angklung dengan benar dan posisi tubuh yang benar saat memainkan angklung. Masing-masing siswa memegang satu angklung dengan nada yang berbeda-beda, sebelum itu siswa diberitahu bahwa disetiap angklung terdapat angka yang membedakan setiap angklungnya sesuai urutan nada, dan mereka harus mengingat angklung angka berapa yang mereka mainkan.

\section{b. Pengenalan Simbol Jari Tangan}

Setelah siswa mendapatkan pengetahuan dan pemahaman mengenai angklung dan cara memainkannya, selanjutnya mulai berlatih menggunakan simbol jari tangan sederhana, setiap siswa harus mengingat angka berapa angklung yang dimainkan, dan harus fokus melihat pelatih atau pengajar saat proses latihan, karena pengajarlah yang akan memberikan simbol 
jari tangan sebagai penentu angklung mana yang akan dibunyikan. Dibawah ini ada gambar simbol jari tangan yang digunakan dalam pelatihan angklung di SDI Mutiara Hati.

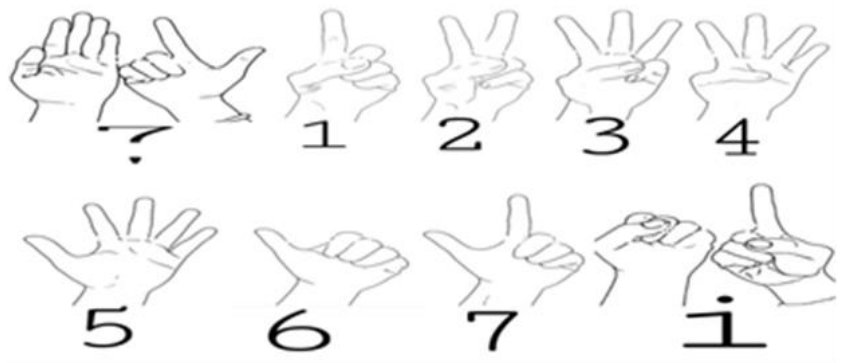

Gambar 3. Simbol Jari Tangan

Keterangan, gambar: $1=\mathrm{d} 0,2=\mathrm{re}, 3=\mathrm{mi}, 4=\mathrm{fa}, 5=\mathrm{sol}, 6=\mathrm{la}, 7=\mathrm{si}, 1$ titik diatas $=$ Do tinggi, 7 titik dibawah $=$ (si) rendah. Untuk membiasakan siswa bermain angklung sambil melihat simbol dari pelatih membutuhkan konsentrasi dan kesabaran, pada awalnya siswa belajar dari (1- i) atau do sampai do tinggi (satu oktaf) secara berurutan, walaupun masih kesulitan dan terkadang lupa membunyikan angklung. tapi seiring berjalannya waktu dan latihan terus menerus, pada akhirnya siswa terbiasa menggunakan simbol jari.

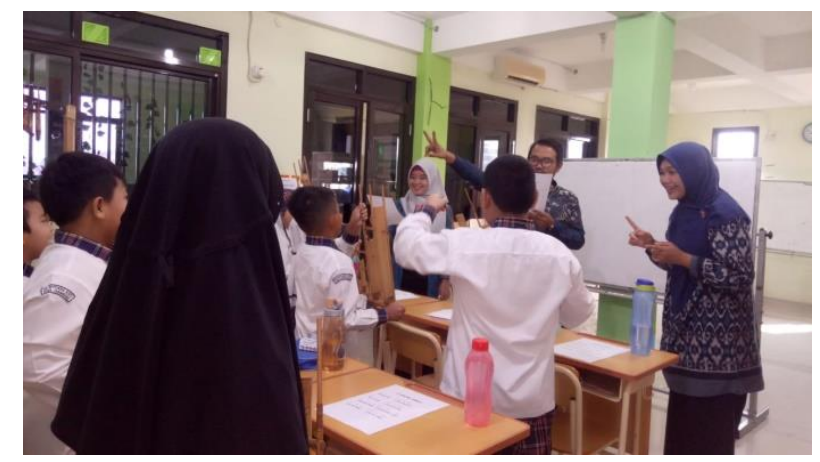

Gambar 4. Penggunaan Simbol Jari Tangan

\section{c. Pemilihan lagu}

Setelah siswa mulai terbiasa memainkan angklung dengan membaca simbol jari tangan, maka pelatih selanjutnya memilih lagu sederhana agar proses pembelajaran angklung lebih menarik. Dan disini peneliti memilih lagu twinkle-twinkle little star, peneliti memilih lagu tersebut karena mudah dipelajari bagi pemula dan cocok untuk anak SD kelas 3 karena mereka pasti hafal dengan lagu tersebut. Hal ini akan membantu jalannya proses pelatihan semakin efektif. Dapat dipahami bahawa hanya beberapa kali latihan mereka sudah hafal dengan bagian bunyi masing-masing angklung.

Pemilihan lagu yang tepat sangat penting, lagu harus disesuaikan dengan kemampuan dan karakteristik siswa, karena di SD Mutiara Hati yang mengikuti kefiatan pelatihan angklung siswa kelas 3 jadi lagu yang dipilih oleh pelatih harus sesuai dengan anak kelas 3 SD. Maka dari itu awal belajar memainkan lagu dengan alat musik angklung menggunakan lagu Twinkletwinkle little star. 


\section{d. Evaluasi}

Tahapan selanjutnya adalah evaluasi, peneliti harus mempunyai catatan lapangan saat proses pelatihan, melalui dokumentasi ataupun secara tertulis, hal ini agar pelatih memiliki data atau catatan faktor penghambat dalam proses latihan angklung. Untuk pelatihan angklung di SD Mutiara Hati kendala yang dimiliki tidak begitu berarti, karena sarana dan prasarana sudah mendukung, masalah yang terjadi saat pelatihan berlangsung yang pertama adalah masalah tempo, karena memainkan angklung itu secara berkelompok dan untuk menyamakan atau menyelaraskan tempo tidak mudah, butuh waktu lahtihan yang terus menerus.

Masalah yang kedua adalah saat siswa sudah merasa bisa membawakan lagu, padahal temponya masih belum rapi siswa terkadang jenuh dan ingin memainkan lagu yang baruu. Setelah melakukan evaluasi pembelajaran atau pelatihan angklung, selanjutnya mempersiapkan kembali lagu yang akan dipelajari oleh siswa, lagu yang dipilih harus yang sesuai dengan peserta atau siswa

\section{Kesimpulan}

Berdasarkan hasil pengamatan serta pembahasan di atas dapat disimpulkan bahsa, mengajar angklung untuk anak Sekolah Dasar tidak mudah, apalagi untuk siswa kelas 3, namun dengan dibantu menggunakan simbol jari sederhana, proses pelatihan angklung berjalan lebih mudah dan efektif, siswa merasa proses pembelajaran angklung lebih seru, karena mereka harus berkonsentrasi melihat simbol yang diberikan pelatih. Hal ini membuat pelatihan angklung jadi menyenangkan dan lebih mudah.

Pemilihan lagu yang akan digunakan dalam pelatihan angklung harus disesuaikan dengan peserta, untuk di SD Mutiara Hati pelatih menggunakan lagu Twinkle-twinklw little star untuk pembelajaran awal lagu, hal ini karena siswa sudah hafal lagunya dan menyukainya. karena memang mereka lebih mudah belajar angklung dengan menyanyikan lagu yang sudah mereka hafal. Penggunaan simbol jari tangan sangat mempermudah proses pelatihan atau pembelajaran angklung dibandingkan hanya membaca notasi angka.

\section{Daftar Pustaka}

Febriyanto, B. (2016). Penerapan model cooperative integrated reading and composition dalam pembelajaran keterampilan membaca pemahaman. Jurnal cakrawala pendas, vol 2, no 1.

Kamus Besar Bahasa Indonesia. (1999). Jakarta: Balai Pustaka.

Kurniawan, EY. (2020). The Use of Action Research Method in Angklung Training for Elementary School Teachers at SDN Sukasari II. Atlantis Press

Makmun. (1995). Perkembangan Anak. Bandung: Remaja Rosdakarya

Nawawi, H. (1995). Metode Penelitian Bidang Sosial. Yogyakarta: Gajah Mada University Press.

Saputra, At Al. (2019). Use ladder snack media inn improving student learning outcomes in mathematics learning in elementary school. Journal of physics: conference series, Ser. 1363 012058

Saputra, D.S. (2017). Interactive learning dalam pembelajaran speaking di kelas V Sekolah Dasar. Jurnal cakrawala PENDAS, Vol 3 No. 1.

Siyanto, S \& Sodik, A. (2015). Dasar Metodologi Penelitian. Yogyakarta: Literasi Media Publishing.

Soharto, M. (1989). Pelajaran Seni Musik. Jakarta: Gramedia

Sudjana. (2005). Strategi Pembelajaran. Bandung: Falah Production.

Sugiyono. (2014). Metode Penelitian Manajemen. Bandung: Alfabeta 